\title{
Estudos cinéticos de sistemas de coberturas alcalinas em pilha de estéril para a prevenção de drenagem ácida de mina
}

\author{
Flávia Cristina Murta ${ }^{1}$, Adilson do Lago Leite ${ }^{2}$ \& Hernani Mota de Lima ${ }^{3}$
}

\begin{abstract}
Resumo A drenagem ácida apresenta-se como um dos grandes problemas da mineração em regiões que possuem minerais sulfetados. Tal fenômeno está ligado especificamente ao processo de oxidação destes minerais, na presença de água, oxigênio e bactérias. Particularmente, o problema da drenagem ácida é crítico na mina de urânio Osamu Utsumi, pertencente às Indústrias Nucleares do Brasil (INB), Caldas MG. Nela há geração de drenagem ácida em diversos locais, incluindo as grandes pilhas de estéril presentes, o reservatório da cava da mina e outros. Sendo assim, o objetivo desta dissertação foi avaliar medidas de remediação passiva para a drenagem ácida de uma das pilhas de estéril desta mina, utilizando-se para este fim colunas de lixiviação em laboratório. Os resultados obtidos mostram que a adição de bentonita foi eficiente na diminuição da infiltração de água na coluna, não alterando, porém, a qualidade do lixiviado. Por sua vez, nas proporções utilizadas, a adição de cal hidratada e dolomita aumentaram o $\mathrm{pH}$ do lixiviado um ponto em média, comprovando suas qualidades em combater a drenagem ácida. Resultados de potencial de oxiredução, acidez, sulfato e alguns metais também são apresentados.
\end{abstract}

Palavras-chave: Drenagem ácida de mina, remediação passiva, colunas de lixiviação.

\begin{abstract}
Kinetic study of covering alkaline systems of waste rock piles to prevent acid mine drainage. Acid drainage is one of the greatest environmental concerns where sulfide minerals are mined. Such process is related to the oxidation of these minerals in the presence of water, oxygen and bacteria. Particularly, this problem is quite expressive in the Osamu Utsumi uranium mine, owned by the Industrias Nucleares do Brasil (INB), Caldas, MG. In this mine acid drainage is generated at several places, including the existent waste rock piles, open pit reservoir and others. Therefore this work is aimed at assessing some passive remediation procedures for one of the waste rock piles of the Osamu Utsumi mine and for that laboratory leaching columns were tested. The results have showed that the bentonite addition was effective in decreasing the water infiltration through the column, but no change in water quality was noticed. In turn, the addition of hydrated lime and dolomite raised the leaching $\mathrm{pH}$ in one point as an average, following the mix proportions used. This fact shows the quality of these cover systems to reduce acid drainage. Results of Eh, acidity, sulfate and some metals of the leaching water are also presented.
\end{abstract}

Keywords: Acid mine drainage, passive remediation, leaching column tests.

INTRODUÇÃO A explotação de bens minerais associados a sulfetos, como urânio, chumbo, cobre, ouro, prata e zinco, pode gerar drenagem ácida de mina (DAM). Ela é resultante da oxidação dos minerais sulfetados, principalmente a pirita $\left(\mathrm{FeS}_{2}\right)$, na presença de oxigênio e água. Quando mediadas por bactérias, thiobacillus ferroxidans, por exemplo, a velocidade das reações envolvidas na geração de DAM pode ser aumentada em mais de um milhão de vezes (Sengupta, 1993).

Por sua vez, a redução do $\mathrm{pH}$ dos corpos d'água em decorrência das águas ácidas produz a solubilização de metais pesados como $\mathrm{Cu}, \mathrm{Ni}, \mathrm{Cd}, \mathrm{Zn}, \mathrm{Pb}, \mathrm{Cr}, \mathrm{Fe}, \mathrm{Hg}$, $\mathrm{Mn}$ e $\mathrm{U}$, diminuindo significativamente sua qualidade.

Existem métodos que prevêem o potencial de geração ácida e são classificados como estáticos ou cinéticos. Estes têm como objetivo determinar se um certo volume de resíduos de mina gerará ácido e pre- ver a qualidade da drenagem baseado na taxa de formação ácida medida (U.S.EPA, 1994).

Os testes estáticos determinam o ácido total gerado e ácido total potencialmente neutralizado de uma amostra, como Acid Base Accounting (ABA) e o método de determinação do potencial de acidez utilizando 30\% de peróxido de hidrogênio (H2O2) (EMCBC , 2004; Evangelou, 1995).

Os testes cinéticos pretendem imitar os processos encontrados nos locais da mina, normalmente a uma taxa acelerada. Durante a análise econômica das minas, nas fases exploratórias, este método é utilizado para se avaliar medidas mitigadoras a serem implementadas. Como exemplo deste, temos células úmidas e colunas de lixiviação (U.S.EPA, 1994).

Desde o início de suas operações em 1977, DAM tem sido verificada na mina Osamu Utsumi, Caldas, Minas

1 - Programa de Pós-Graduação em Engenharia Ambiental, UFOP, Universidade Federal de Ouro Preto, , Ouro Preto (MG), Brasil. E-mail: fmurta@yahoo.com.br

2 - Departamento de Engenharia Civil da Escola de Minas, UFOP, Ouro Preto (MG), Brasil.

3 - Departamento de Engenharia de Minas da Escola de Minas, UFOP, Ouro Preto (MG), Brasil. 
Gerais. Trata-se da primeira mina de urânio do país, tendo estado em operação até 1995. Pertence às Industriais Nucleares do Brasil (INB) e constitui parte da chamada Unidade de Tratamento de Minérios (UTM). Encontra-se em processo de reabilitação e descomissionamento.

Toda a DAM gerada na área da mina e pilhas de estéril é bombeada a uma estação e submetida a um tratamento ativo que consiste na adição de cal hidratada para elevação do $\mathrm{pH}$ e floculante para precipitação dos complexos formados. Após o tratamento, a água limpa é lançada no ambiente em dois pontos específicos e o resíduo do tratamento é bombeado para a cava da mina, que hoje se constitui em um grande reservatório de águas ácidas. Segundo Cipriani (2002), de 1994 até 2001 aproximadamente 18 milhões de metros cúbicos de DAM foram tratados a um custo de aproximadamente U\$ 1,2 milhões, somente em insumos. A manutenção destes custos é proibitiva, uma vez que se espera que a geração de DAM perdure por séculos.

Desta forma, o presente estudo tem como objetivo avaliar alternativas de remediação passiva para a DAM gerada nas pilhas de estéril. Por remediação passiva entendem-se medidas (obras e ações) que resultem na diminuição dos riscos ambientais e não envolvam o consumo de energia durante todo o seu período de funcionamento. A pesquisa envolveu estudos laboratoriais de lixiviação em colunas utilizando-se de material coletado em uma das pilhas de estéril da mina, especificamente, no, assim chamado, Bota-Fora 8 (BF8).

Os processos de remediação estudados constituíram-se na simulação em laboratório de sistemas de cobertura para a referida pilha, utilizando-se coberturas no topo das colunas. Para isto, materiais alcalinos como cal hidratada $\left(\mathrm{Ca}(\mathrm{OH})_{2}\right)$ e dolomita $\left(\mathrm{CaMg}\left(\mathrm{CO}_{3}\right)_{2}\right)$ foram utilizados, visando aumentar o $\mathrm{pH}$ das águas de infiltração. Ao mesmo tempo, aplicou-se bentonita sódica (material muito expansível) nestas camadas, com o objetivo de diminuir a infiltração.

\section{MATERIAIS E MÉTODOS}

Amostragem A coleta de amostras foi feita em um ponto específico da pilha de estéril BF8. Seu material constituinte provém principalmente das atividades de decapeamento da mina, antes do início de suas operações. O material coletado foi caracterizado de modo a possibilitar a realização de futuras comparações, bem como para melhor conhecimento da amostra submetida aos testes.

$\mathrm{O}$ procedimento envolveu a coleta de material inconsolidado e rocha num local que havia sido remodelado há aproximadamente seis meses antes da data da amostragem. Tomou-se o cuidado de retirar a camada superior de solo (aproximadamente $30 \mathrm{~cm}$ ), que provavelmente já estava bastante alterada em função do trânsito de veículos no local.

Logo após as coletas, as amostras de solo foram quarteadas pelo método do cone e armazenadas em sacos plásticos de $20 \mathrm{~kg}$, sendo estes rotulados e enviados aos laboratórios da Universidade Federal de Ouro Preto para análises. As amostras de rocha também foram devidamente armazenadas e rotuladas.
Caracterização dos Materiais Subdividem-se os ensaios de caracterização da amostra em três categorias: geotécnica, mineralógica e físico-química. A tabela 1 resume os ensaios geotécnicos realizados e as normas da ABNT utilizadas para tal.

A caracterização físico-química consistiu na determinação dos seguintes parâmetros: $\mathrm{pH}$, condutividade elétrica do extrato aquoso, capacidade de troca catiônica e superfície específica.

A determinação do $\mathrm{pH}$ e condutividade elétrica do extrato aquoso (CE) foram realizadas com base nos métodos recomendados por Camargo et al. (1986), os quais para a determinação do $\mathrm{pH}$ adotou-se a relação solo:solução 1:2,5 e para a CE utilizou-se a proporção solo:água de 1:1.

Para a determinação da capacidade de troca catiônica (CTC) e superfície específica (SE) utilizou-se o método recomendado por Pejon (1992), o qual consiste em se adicionar uma solução de azul de metileno a uma suspensão de solo e se observar ao longo do tempo a formação de uma auréola azul persistente em torno da mancha escura.

Para a determinação da composição mineralógica do estéril foram utilizadas as técnicas de difração de raios-X e lâmina petrográfica.

As amostras submetidas à difração de raios-X foram trituradas e peneiradas de modo a se obter granulometria inferior a 200 mesh. O equipamento utilizado foi um difratômetro Rigaku, modelo D/Max-B-series, radiação $\mathrm{Cu}-\mathrm{K} \alpha$ e filtro de níquel.

As lâminas petrográficas foram preparadas com as amostras de rocha coletadas em campo.

Colunas de Lixiviação Os ensaios de colunas de lixiviação foram denominados de I, II, III, IV, V, VI, VII e A (números das colunas). Todos estes ensaios, com exceção do ensaio II, tiveram a duração de 30 dias. Seus procedimentos são descritos a seguir.

CONSTRUÇÃO DAS COLUNAS As colunas I a VII foram construídas em tubos de PVC (cloreto de polivinila), com dimensões de 75,6 mm de diâmetro e 1,045 $\mathrm{m}$ de altura, sendo suportadas por uma base também de PVC, como mostra a figura 1 .

Tabela 1 - Ensaios geotécnicos realizados e suas respectivas normas.

\begin{tabular}{l|l}
\hline Ensaios Realizados & Normas ABNT \\
\hline Peneiramento Grosso & 7181 \\
\hline Peneiramento Fino & 7181 \\
\hline Sedimentação & 7181 \\
\hline Limites de Atterberg & 6459 e 7180 \\
\hline Massa Específica dos Sólidos & 6508 \\
\hline Condutividade Hidráulica & 13292 \\
\hline
\end{tabular}


Tais colunas possuíam um orifício de aproximadamente $12 \mathrm{~mm}$ de diâmetro em seu topo para a entrada de água e ar, o qual permanecia aberto durante os ensaios e também um orifício de 13,6 mm de diâmetro na parte inferior da coluna para escoamento do lixiviado.

Para o ensaio da Coluna A foi utilizada uma proveta vítrea de $1000 \mathrm{~mL}$, com diâmetro de $59,35 \mathrm{~mm}$.

PROCEDIMENTOS DE ENSAIO De forma geral os ensaios consistiram em se percolar água destilada-deionizada pelas amostras e pelos sistemas de cobertura, monitorando-se diversos parâmetros químicos e físico-químicos do lixiviado. Os materiais lixiviados dentro das colunas encontravam-se em seu teor de umidade higroscópica.

A quantidade de água a ser inserida nas colunas foi calculada com o intuito de se simular a precipitação ocorrida no Complexo Mineiro Industrial do Planalto de Poços de Caldas (CIPC) por um período de um ano. Para este cálculo considerou-se a área transversal da coluna, que é de $4.488,83 \mathrm{~mm}^{2}$, e a precipitação média anual de $1.700 \mathrm{~mm}$ no CIPC. Sendo assim, previa-se a adição de $1.908 \mathrm{~mL}$ por semana, totalizando-se um volume mensal de $7.632 \mathrm{~mL}$. Obviamente, o volume semanal de $1.908 \mathrm{~mL}$ somente foi respeitado quando houve percolação suficiente, de forma a não haver acúmulo excessivo de água dentro da coluna.

Durante os ensaios o $\mathrm{pH}$ do lixiviado foi analisado diariamente e os parâmetros acidez, condutividade elétrica, $\mathrm{SO}_{4}^{2-}, \mathrm{Ca}, \mathrm{Mg}, \mathrm{Na}, \mathrm{K}, \mathrm{Al}, \mathrm{Fe}, \mathrm{Mn}$ e $\mathrm{Zn}$ foram analisados semanalmente.

A tabela 2 mostra um resumo geral da composição dos sistemas de cobertura das colunas. Eles consistiram em camadas de $5 \mathrm{~cm}$ de altura colocadas em seu topo, acima da amostra $(95 \mathrm{~cm})$, sendo compostas de misturas alternadas de amostra, cal hidratada $\left(\mathrm{Ca}(\mathrm{OH})_{2}\right)$, dolomita $\left(\mathrm{CaMg}\left(\mathrm{CO}_{3}\right)_{2}\right)$ e bentonita em diferentes proporções (peso seco). Estes sistemas, por sua vez, foram montados em frascos de polietileno (PET) com diâmetro de aproximadamente $70 \mathrm{~mm}$, apresentando várias perfurações em sua base para se aumentar a percolação. Ao fundo do frasco foi adicionada uma camada de geotêxtil muito permeável, que teve a função de filtro contra a percolação de finos (argilas e siltes). O acréscimo de água destilada-deionizada era feito no topo da coluna, junto aos sistemas de coberura, quando presentes.

A Coluna I objetivou funcionar como referência para as outras colunas, sendo totalmente preenchida com a amostra coletada, sem a presença de sistema de cobertura.

A função do sistema de cobertura da Coluna II foi avaliar o efeito da adição de bentonita na infiltração de água e também na qualidade do lixiviado coletado. O sistema de cobertura da Coluna III teve os mesmos objetivos do sistema da Coluna II, diferenciando-se pela quantidade de bentonita adicionada, que foi de 2,3\%. Como será visto mais adiante, a infiltração de água na Coluna II foi pequena, justificando a redução na quantidade de bentonita citada.

O objetivo dos sistemas de cobertura das colunas IV, V, VI e VII foi avaliar a diminuição da infiltração dada pela adição de bentonita e o aumento na alcalini-

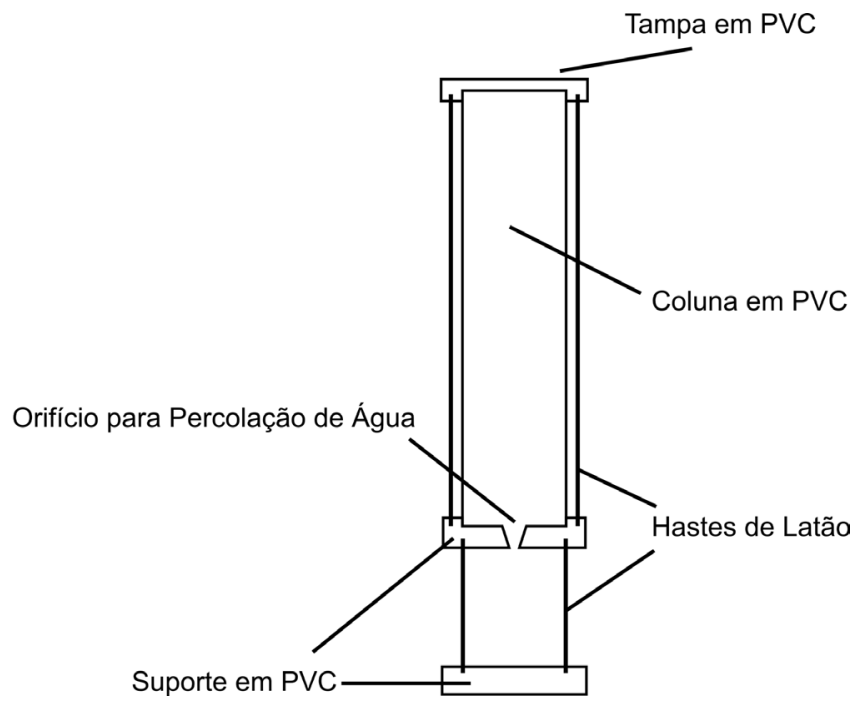

Figura 1 - Seção esquemática longitudinal da coluna de lixiviação.

Tabela 2 - Composição dos sistemas de cobertura (\% peso seco).

\begin{tabular}{l|c|c|c|c}
\hline Colunas & $\begin{array}{c}\text { Amostra } \\
\text { BF } 8\end{array}$ & $\begin{array}{c}\text { Bentonita } \\
\text { Sódica }\end{array}$ & $\begin{array}{c}\text { Cal } \\
\text { Hidratada }\end{array}$ & Dolomita \\
\hline Coluna I & $100 \%$ & & & \\
\hline Coluna II & $95,47 \%$ & $4,53 \%$ & & \\
\hline Coluna III & $97,70 \%$ & $2,30 \%$ & & \\
\hline Coluna IV & $88 \%$ & $2 \%$ & $10 \%$ & \\
\hline Coluna V & $88 \%$ & $2 \%$ & & $10 \%$ \\
\hline Coluna VI & $78 \%$ & $2 \%$ & $20 \%$ & \\
\hline Coluna VII & $78 \%$ & $2 \%$ & & $20 \%$ \\
\hline
\end{tabular}

dade do lixiviado através da utilização da cal hidratada ou dolomita. As proporções utilizadas tiveram, em um primeiro instante, caráter exclusivamente especulativo. Posteriormente, a depender dos resultados obtidos, deverão ser conduzidas avaliações econômicas sobre a utilização destes materiais em sistemas de cobertura nas pilhas de estéril da mina.

A Coluna A, realizada em uma proveta vítrea, foi preenchida com a amostra coletada, sendo posteriormente saturada com água destilada-deionizada. Com este ensaio pretendia-se avaliar o comportamento químico e físico-químico da água dos poros da amostra sob condições de total saturação. O pH e o Eh da solução de saturação foram analisados diariamente e os demais parâmetros semanalmente.

ANÁLISES QUÍMICAS DO LIXIVIADO A determinação da condutividade elétrica $(\mathrm{CE}) \mathrm{e} \mathrm{pH}$ foi feita 
com o uso de um aparelho Ultrameter, Modelo 6P, cuja calibragem foi realizada com soluções tampões da marca Nuclear, sendo executadas imediatamente após a coleta do lixiviado.

As determinações dos metais foram realizadas em um Espectrofotômetro de Emissão Atômica com Fonte Plasma, com Visão Radial, marca Spectro, modelo Ciros CCD. Para isso foram armazenadas alíquotas de $50 \mathrm{~mL}$ em frascos de polietileno, devidamente acidificadas com $\mathrm{HNO}_{3} 10$ mol.L-1 para se evitar possíveis reações de precipitação.

As determinações do sulfato $\left(\mathrm{SO}_{4}^{2-}\right)$ foram realizadas em um Espectrofotômetro da marca Merck, modelo SQ 118. As concentrações de sulfato nas amostras, em mg. $\mathrm{L}^{-1}$, foram obtidas através de uma curva-padrão.

Para a determinação da acidez e alcalinidade utilizou-se o método titulométrico descrito pelo APHA (1992).

\section{RESULTADOS E DISCUSSÕES}

Caracterização dos Materiais Com a curva de distribuição granulométrica construída, foi possível se obter as frações granulométricas da amostra coletada, mostradas na tabela 3 , indicando tratar-se de um pedregulho areno-siltoso. $\mathrm{O}$ índice de plasticidade (IP) medido $(0,4 \%)$ denota plasticidade muito baixa para a amostra.

A condutividade hidraúlica $(K)$ determinada foi $2 \times 10^{-3} \mathrm{~cm} \cdot \mathrm{s}^{-1}$, considerada alta. Acredita-se que o valor de $K$ do BF8 como um todo seja alto por duas razões: $1^{\text {a) }}$ A granulometria do BF8 pode ser considerada grosseira, envolvendo até matacões métricos, como observado em campo; $2^{a}$ ) não foram observadas obras de drenagem superficial na área interna do BF8 e nem feições erosivas, o que leva a conclusão de que praticamente toda a água meteórica se infiltra, com baixo escoamento superficial.

As características físico-químicas da amostra são apresentadas na tabela 4. É possível se observar o baixo valor de $\mathrm{pH}$, denotando acidez na amostra. Considerando-se a razão solo-solução $(1: 2,5)$ e o tempo de contato (30 minutos) utilizados, conclui-se que a geração de acidez é bastante rápida quando do contato da água com a amostra. Por outro lado, os valores de CTC e SE da tabela 4 mostram que a amostra não é muito reativa, o que já se esperava em função da baixa plasticidade obtida.

A difratometria de raios- $\mathrm{X}$ evidenciou principalmente a presença de ortoclásio $\left(\mathrm{KAlSi}_{3} \mathrm{O}_{8}\right)$, muscovita $\left((\mathrm{K}, \mathrm{Na}) \mathrm{Al}_{2}(\mathrm{Si}, \mathrm{Al})_{4} \mathrm{O}_{10}(\mathrm{OH})_{2}\right)$ e, em menor proporção, caulinita $\left(\mathrm{Al}_{2} \mathrm{Si}_{2} \mathrm{O}_{5}(\mathrm{OH})_{4}\right)$. Tal mineralogia é compatível com as rochas alcalinas presentes na região e com o estado de alteração da amostra. Por outro lado, ela também é compatível com os resultados das caracterizações geotécnica e físico-química.

Destaca-se que a pirita não foi detectada por este método. Segundo Souza (1996) ela ocorre no local em porcentagens menores que $0,2 \%$ em peso do total da rocha, não detectável pelo referido método, com tamanho aproximado de $80 \mu \mathrm{m}$, o que confere ao mineral reatividade química intermediária.

Não foi possível a identificação mineralógica
Tabela 3 - Frações granulométricas da amostra estudada.

\begin{tabular}{l|l}
\hline Fração Granulométrica & Porcentagem \\
\hline Argila & 8,5 \\
\hline Silte & 22,5 \\
\hline Areia fina & 6 \\
\hline Areia média & 7 \\
\hline Areia grossa & 10 \\
\hline Pedregulho & 46 \\
\hline
\end{tabular}

Tabela 4 - Características fisico-químicas da amostra coletada.

\begin{tabular}{l|l}
\hline Parâmetros & Amostra BF8 \\
\hline $\mathrm{pH}$ & 4,61 \\
\hline Condutividade Elétrica (CE) & $110,3 \mu \mathrm{Scm}{ }^{-1}$ \\
\hline Superficíe Específica (SE) & $3,78 \mathrm{~m} / \mathrm{g}$ \\
\hline Capacidade de Troca Catiônica (CTC) & $0,48 \mathrm{cmol} / \mathrm{kg}$ \\
\hline Massa Específica & $2,969 \mathrm{~g} \cdot \mathrm{cm}^{1-}$ \\
\hline Condutividade Hidráulica (K) & $2 \times 10^{3-} \mathrm{cm}^{-1}$ \\
\hline
\end{tabular}

das amostras de rocha através de lâminas petrográficas devido à alteração avançada das mesmas.

\section{Colunas de Lixiviação}

POTENCIAL HIDROGENIÔNICO $(p H)$ A figura 2 apresenta os resultados de $\mathrm{pH}$ ao longo dos 30 dias de ensaio para as colunas I a VII, com exceção da Coluna II. Nesta última não houve percolação durante o tempo de ensaio, mostrando o efeito da bentonita $(4,53 \%$, peso seco) no seu sistema de cobertura para a diminuição da taxa de infiltração.

O gráfico da Coluna I mostra que desde o primeiro momento de contato da amostra com a água há redução do $\mathrm{pH}$, estando este compreendido entre 4,07 e 4,68 durante todo o período de ensaio.

Através dos volumes coletados ao longo dos 30 dias de ensaio, foi possível observar que a quantidade de 2,3\% de bentonita no sistema de cobertura da Coluna III também resultou em diminuição na taxa de infiltração em relação à Coluna I (referência). Os valores de $\mathrm{pH}$ da Coluna III variaram entre 3,90 e 4,54.

Esperava-se que na Coluna III houvesse alguma elevação do $\mathrm{pH}$ do lixiviado em relação à Coluna I, já que o pH medido para a bentonita foi de 10,2 (ver Tab. 4). No entanto esta suposição não foi confirmada, sendo os valores do $\mathrm{pH}$ menores que os da Coluna I a partir do vigésimo terceiro dia de ensaio. Conclui-se 


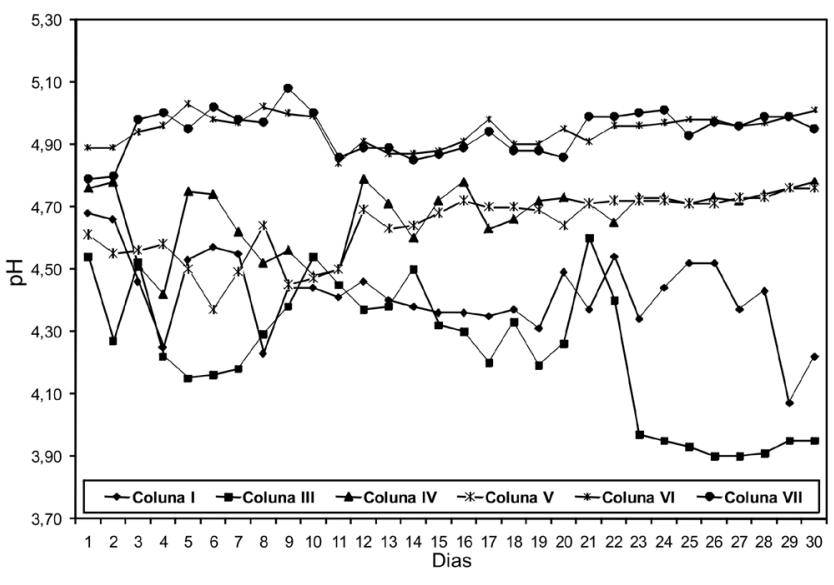

Figura 2 - Variação do pH nas drenagens das colunas I, III, IV, V, VI e VII ao longo do tempo.

que a bentonita, na proporção utilizada, não é efetiva na melhoria das condições de $\mathrm{pH}$ do lixiviado da amostra, atuando somente na redução da taxa de infiltração.

Observando-se as curvas das colunas IV, V, VI e VII, nota-se uma crescente elevação do $\mathrm{pH}$ com a utilização dos sistemas de cobertura propostos, comprovando a eficiência técnica dos mesmos. A utilização de uma concentração maior de cal hidratada ou dolomita mostrou-se mais eficiente para manter estes valores na faixa estabelecida para o $\mathrm{pH}$ natural dos corpos d'água. Tanto o uso de cal hidratada, quanto o de dolomita são efetivos para elevarem os valores de $\mathrm{pH}$ e não apresentam diferenças significativas quanto aos valores absolutos encontrados ao final do ensaio.

A figura 3 apresenta a evolução do $\mathrm{pH}$ do lixiviado nas colunas I e A. Os valores de $\mathrm{pH}$ da Coluna A oscilaram entre 6,92 e 5,09, apresentando alguma estabilização a partir do vigésimo dia. Comparando-se os gráficos das colunas I e A, percebe-se que mesmo inundada, a amostra gerou acidez, comprovada pela diminuição sistemática do $\mathrm{pH}$ ao longo do tempo. $\mathrm{O} \mathrm{pH}$ da água destilada-deionizada utilizada nos ensaios se situou em torno de 5,85 e 6,03.

Os valores de $\mathrm{pH}$ encontrados para as colunas anteriormente referidas foram comparados aos padrões de lançamento de efluentes que dispõe a Deliberação Normativa COPAM 10/1986 (COPAM, 1986). Segundo esta, os efluentes somente poderão ser lançados nos corpos de água se o pH estiver entre 6,5 e 8,5 (+/- 0,5). Conclui-se que apesar da crescente elevação do $\mathrm{pH}$ com os tratamentos propostos, a quantidade de material alcalino utilizada não foi suficiente para elevar o $\mathrm{pH}$ do lixiviado aos níveis estabelecidos pela legislação.

ACIDEZ A figura 4 traz a evolução da acidez do lixiviado para os ensaios das Colunas I, IV, V, VI e VII. Percebe-se uma elevação inicial deste parâmetro se comparado à Coluna I (referência). Por outro lado, é notável a tendência de redução da acidez ao longo do tempo apresentada por estas colunas. Diante dos siste-

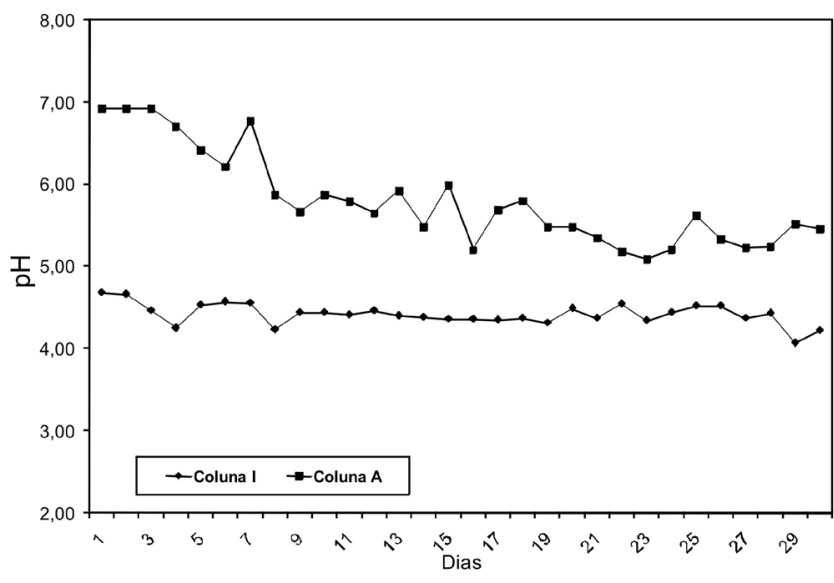

Figura 3 - Variação do pH nas drenagens das colunas I e A ao longo do tempo.

mas de cobertura aplicados, nos quais se utilizou bentonita, cal hidratada e dolomita, o aumento de acidez em relação à Coluna I não era esperado.

A hipótese formulada para a origem desta acidez está relacionada à presença da bentonita sódica, que, por sua vez, poderia estar liberando $\mathrm{Al}^{3+}$ ou outros cátions metálicos ao meio, de forma a contribuir diretamente para a geração de acidez. Tal hipótese carece de maior investigação.

Vale notar que no geral os valores absolutos de acidez são um pouco maiores nas colunas IV e V em relação às colunas VI e VII, o que era esperado, uma vez que as quantidades de cal hidratada e dolomita aumentaram para $10 \%$ para $20 \%$ nestas últimas colunas. Entretanto, ao se comparar às tendências mostradas nas figuras, não se percebem diferenças consideráveis de acidez ao final dos ensaios. Conclui-se então que, em termos de acidez, o aumento de 10 para $20 \%$ de cal hidratada e dolomita não surtiu grande efeito para um mês de ensaio.

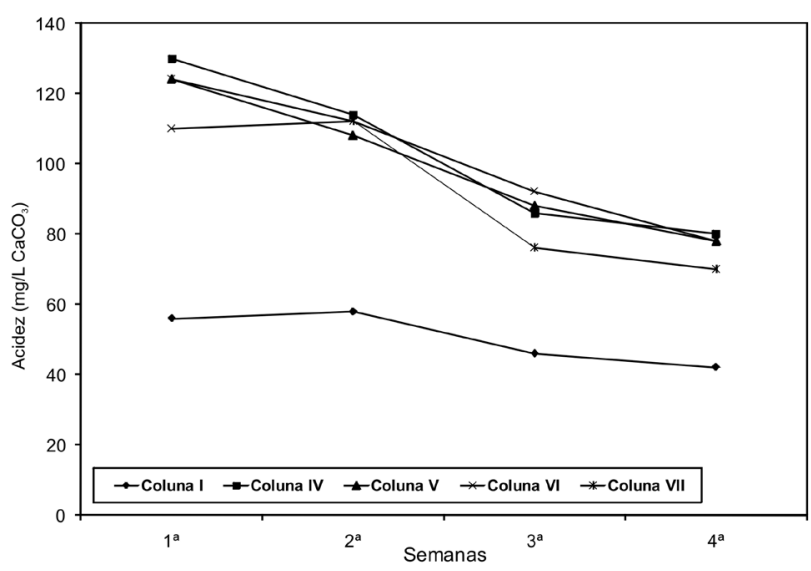

Figura 4 - Variação da acidez nas drenagens das colunas I, IV, V, VI e VII ao longo do tempo. 
A acidez medida para o ensaio da Coluna A (Fig. 5), como esperado, foi inferior à encontrada para a Coluna I. Lembra Souza (1996) que a solubilização da pirita ocorre também em condições anaeróbias, contudo em uma velocidade muito reduzida. Sendo assim, a liberação de acidez para o meio é menor que em condições aeróbias.

CONDUTIVIDADE ELÉTRICA (CE) Observa-se na figura 6 que os valores de condutividade elétrica do lixiviado das colunas IV, V, VI e VII foram muito superiores aos da Coluna I. Isto provavelmente ocorreu devido à introdução de aditivos alcalinos e bentonita nestas colunas. A condutividade elétrica do extrato aquoso da bentonita é de $2370 \mu \mathrm{S} . \mathrm{cm}^{-1}$, considerada alta, mostrando grande concentração de íons na superfície deste mineral.

Também se observa uma redução deste parâmetro ao longo do tempo. Ao final dos 30 dias de ensaio os valores de CE das colunas IV a VII convergem todos para aproximadamente $250 \mu \mathrm{S} . \mathrm{cm}^{-1}$.

Por outro lado, inicialmente os valores de CE das colunas IV e V são maiores que os valores das colunas VI e VII. Lembrando que a quantidade de cal hidratada e dolomita utilizada nos sistemas de cobertura foram maiores nas colunas VI e VII, respectivamente, infere-se que a elevação do $\mathrm{pH}$ nestas colunas favoreceu a formação de alguns precipitados, reduzindo desta forma a quantidade de íons em solução, resultando em diminuição da $\mathrm{CE}$.

Ao se analisar a figura 7, a qual mostra os valores de CE das colunas I e A ao longo do tempo, percebe-se que os valores da Coluna I são bem superiores aos da Coluna A. Como na região saturada a presença de oxigênio é bem menor que na região não saturada, sua cinética de lixiviação é menor e consequentemente a presença de íons na coluna A será muito menor. Ao mesmo tempo, observa-se bastante redução de CE com o tempo para a Coluna I (referência) e pouca redução na Coluna A.

SULFATO As concentrações de sulfato no lixiviado das colunas I, IV, V, VI e VII são apresentadas na figura 8. Em todas as colunas, a concentração deste elemento no lixiviado foi maior que na Coluna I, e tal qual nesta última, ela se reduziu com o tempo. É notável que as concentrações das colunas IV, V, VI e VII praticamente se igualaram a partir da segunda semana de ensaio.

Investigando-se o porquê das maiores concentrações de sulfato no lixiviado das colunas IV a VII em relação à Coluna I, em Souza (1996) foram encontradas algumas indicações do que possa ter acontecido. Provavelmente isto ocorreu devido a reações de dissolução de materiais alcalinos como a dolomita e a cal hidratada pelo ácido sulfúrico formado. Tais reações liberam íons $\mathrm{SO}_{4}{ }^{2-}$, que se não forem precipitados, serão lixiviados.

Ao observar a variação da concentração de sulfato da Coluna A (Fig. 9), tem-se valores compreendidos entre 1,82 e 2,35 mg.L ${ }^{-1}$. Em relação à Coluna I que apresenta valores entre 11,06 a $26,78 \mathrm{mg} \cdot \mathrm{L}^{-1}$, eles são bastante reduzidos. Acredita-se que esta diferença seja decorrente da velocidade de oxidação da pirita, que por sua vez tem

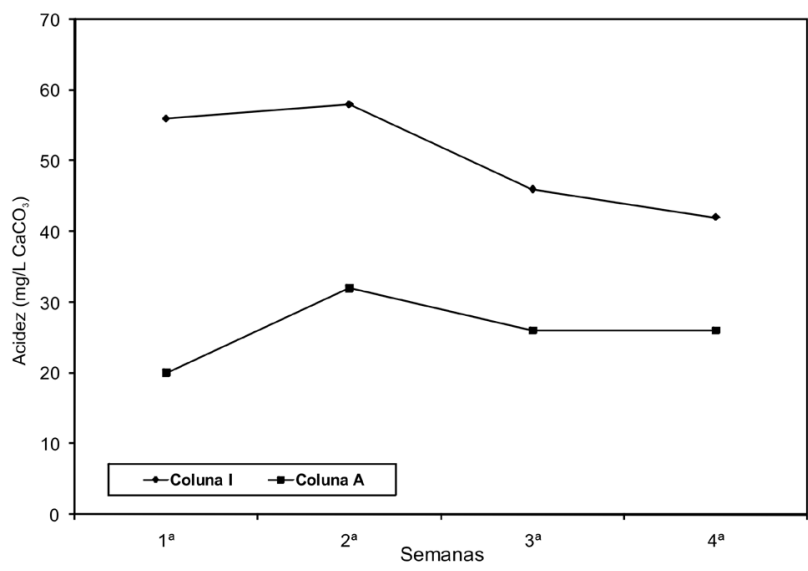

Figura 5 - Variação da acidez nas drenagens das colunas I e A ao longo do tempo.

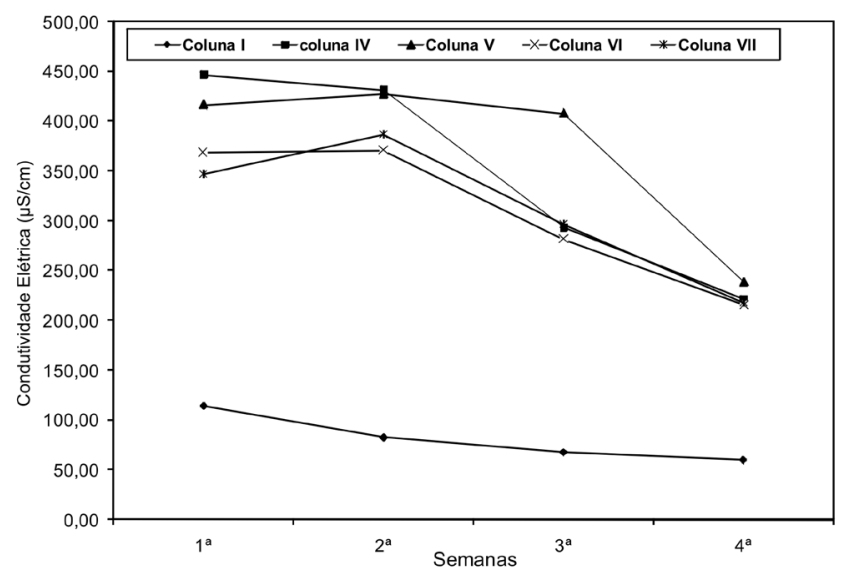

Figura 6 - Variação da condutividade elétrica nas drenagens das colunas I, IV, V, VI e VII ao longo do tempo.

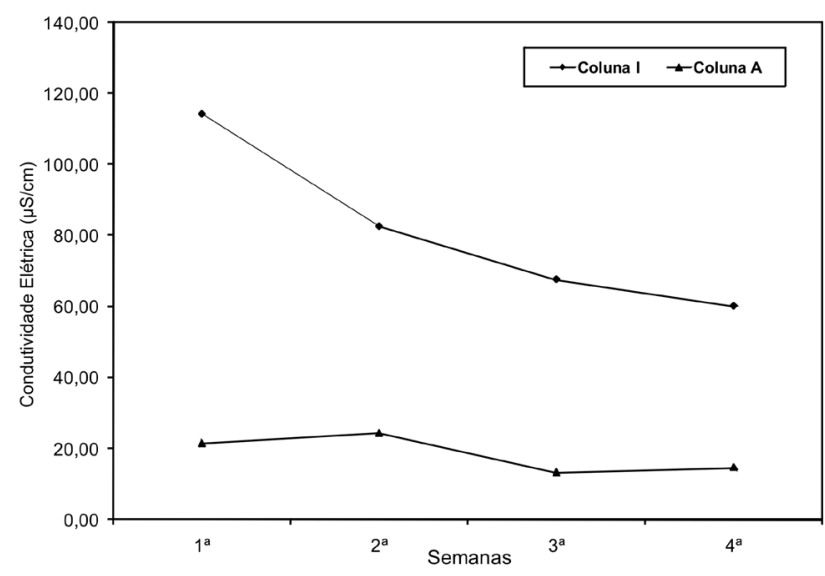

Figura 7 - Variação da condutividade elétrica nas drenagens das colunas I e A ao longo do tempo. 


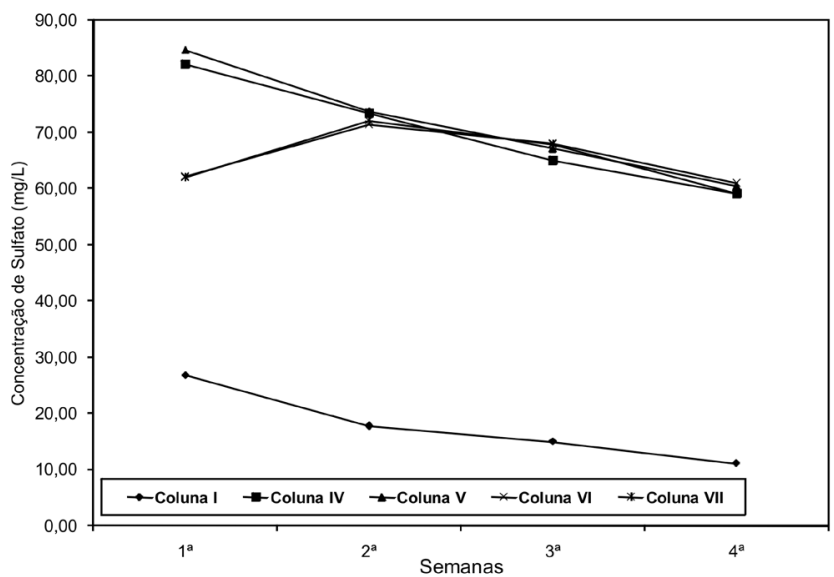

Figura 8 - Variação da concentração de sulfato nas drenagens das colunas I, IV, V, VI e VII ao longo do tempo.

como subproduto íons sulfato. Em condições anaeróbias, como no caso da Coluna A, esta velocidade é menor do que em condições aeróbias, como na Coluna I.

METAIS As seguintes espécies químicas foram analisadas nos lixiviados das colunas: $\mathrm{Ca}, \mathrm{Mg}, \mathrm{Na}, \mathrm{K}, \mathrm{Al}$, $\mathrm{Fe}, \mathrm{Mn}$ e Zn. As concentrações máximas e mínimas obtidas para o lixiviado são apresentadas na tabela 5 .

A título de comparação, as concentrações de ferro, manganês e zinco foram comparadas com os padrões para o lançamento de efluentes da Deliberação Normativa COPAM 10/1986 (COPAM, 1986), também mostrados na tabela 5. Esta comparação mostrou que somente a concentração de manganês ultrapassou os referidos padrões, acrescentando-se o fato de que isto aconteceu para todas as colunas ensaiadas.

Nota-se também que as concentrações da Coluna III foram superiores às da Coluna I, sugerindo que

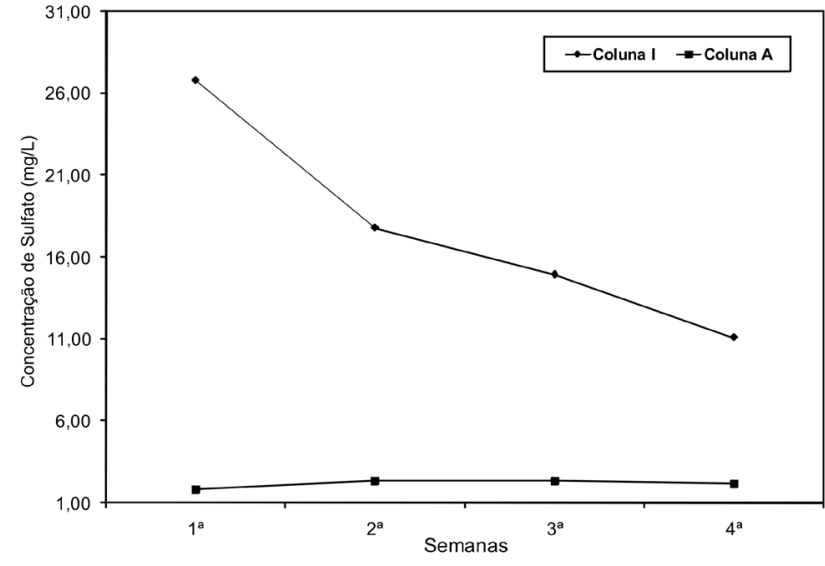

Figura 9 - Variação da concentração de sulfato nas drenagens da coluna I e A ao longo do tempo.

os metais contidos na bentonita possam ter contribuído para a elevação das concentrações no lixiviado. Por este motivo, a concentração dos metais também foi determinada para a bentonita. Esta determinação foi feita através da digestão da bentonita seca em meio ácido, em temperaturas que alcançaram $140^{\circ} \mathrm{C}$. A tabela 6 apresenta os respectivos resultados, observando-se concentrações relativamente altas para todos os metais analisados, principalmente para o $\mathrm{Fe}, \mathrm{Al}, \mathrm{Mg}$ e $\mathrm{Na}$. Estas concentrações confirmam a possibilidade descrita anteriormente.

Nas figuras 10 a 13 são apresentados gráficos da concentração dos metais em função do tempo.

As figuras 10 a 13 mostram que houve um acréscimo nas concentrações de todos os metais analisados para as colunas IV, V, VI e VII em relação à Coluna I (referência). Suspeita-se que a utilização da bentonita nas colunas com sistema de cobertura, tenha contribuído para este acréscimo.

Tabela 5 - Concentrações máximas e mínimas de metais nos lixiviados.

\begin{tabular}{|c|c|c|c|c|c|c|c|c|c|c|c|c|}
\hline \multirow{2}{*}{$\begin{array}{l}\text { Parâmetros } \\
\left(\mathrm{mg} \cdot \mathrm{L}^{-1}\right)\end{array}$} & \multicolumn{2}{|c|}{ Coluna I } & \multirow{2}{*}{ Coluna III } & \multicolumn{2}{|c|}{ Coluna IV } & \multicolumn{2}{|c|}{ Coluna V } & \multicolumn{2}{|c|}{ Coluna VI } & \multicolumn{2}{|c|}{ Coluna VII } & \multirow{2}{*}{$\begin{array}{c}\text { COPAM } \\
10 / 86\end{array}$} \\
\hline & Máx. & Mín. & & Mín. & Máx. & Mín. & Máx. & Mín. & Máx. & Mín. & Máx. & \\
\hline Ferro & 0,01 & 0,01 & 0,02 & 0,07 & 0,02 & 0,09 & 0,02 & 0,03 & 0,01 & 0,03 & 0,01 & 10 \\
\hline Manganês & 1,07 & 0,58 & 3,81 & 4,97 & 1,36 & 3,65 & 1,35 & 2,76 & 1,42 & 3,74 & 1,17 & 1 \\
\hline Zinco & 0,35 & 0,17 & 2,14 & 1,20 & 0,46 & 1,66 & 0,48 & 0,76 & 0,49 & 1,07 & 0,40 & 5 \\
\hline Alumínio & 3,49 & 1,26 & 8,69 & 9,08 & 5,33 & 6,86 & 4,13 & 8,56 & 4,12 & 8,02 & 3,90 & \\
\hline Potássio & 4,85 & 2,47 & 13,62 & 11,24 & 7,01 & 11,45 & 6,57 & 8,25 & 6,85 & 9,03 & 6,11 & \\
\hline Cálcio & 4,85 & 1,89 & 17,89 & 27,64 & 11,54 & 34,00 & 10,48 & 19,47 & 14,69 & 23,24 & 7,75 & \\
\hline Magnésio & 0,87 & 0,30 & 2,90 & 4,48 & 1,24 & 4,92 & 1,22 & 3,45 & 1,49 & 4,19 & 1,19 & \\
\hline Sódio & 2,39 & 0,58 & 55,50 & 34,64 & 6,82 & 43,91 & 2,55 & 25,76 & 8,41 & 42,64 & 6,07 & \\
\hline
\end{tabular}


Tabela 6 - Concentração de metais na bentonita.

\begin{tabular}{l|c}
\hline Parâmetros & Concentração $\left(\mathrm{mg} \cdot \mathrm{kg}^{-1}\right)$ \\
\hline Ferro & 56233 \\
\hline Manganês & 303 \\
\hline Zinco & 113 \\
\hline Alumínio & 75100 \\
\hline Potássio & 4575 \\
\hline Cálcio & 2696 \\
\hline Magnésio & 11940 \\
\hline Sódio & 18154 \\
\hline
\end{tabular}

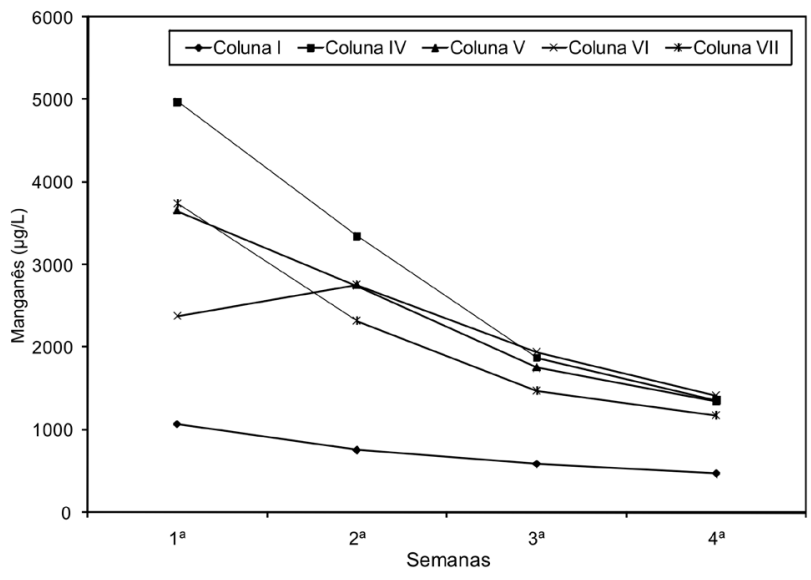

(a)
Nota-se também que ao longo do tempo ocorre uma redução nas concentrações dos metais em todos os ensaios realizados, que pode ser atribuída ao acréscimo nos valores de $\mathrm{pH}$ dos lixiviados e também ao consumo dos elementos ao longo do tempo de lixiviação.

Ao se observar a figura 10(b), que traz as concentrações de ferro para o lixiviado das colunas I, IV, V, VI e VII, percebe-se que as concentrações deste elemento são relativamente baixas. Dois fatores podem explicar tal fato: (i) a concentração de pirita no local ocorre em porcentagens muito pequenas; (ii) o ferro se precipita como hidróxido férrico em valores de $\mathrm{pH}$ acima de 3,5.

Comparando-se as figuras 10(b) e 11(a), observa-se que os lixiviados das colunas I, IV, V, VI e VII têm concentrações de zinco muito superiores às concentrações de ferro, sugerindo que provavelmente mi-

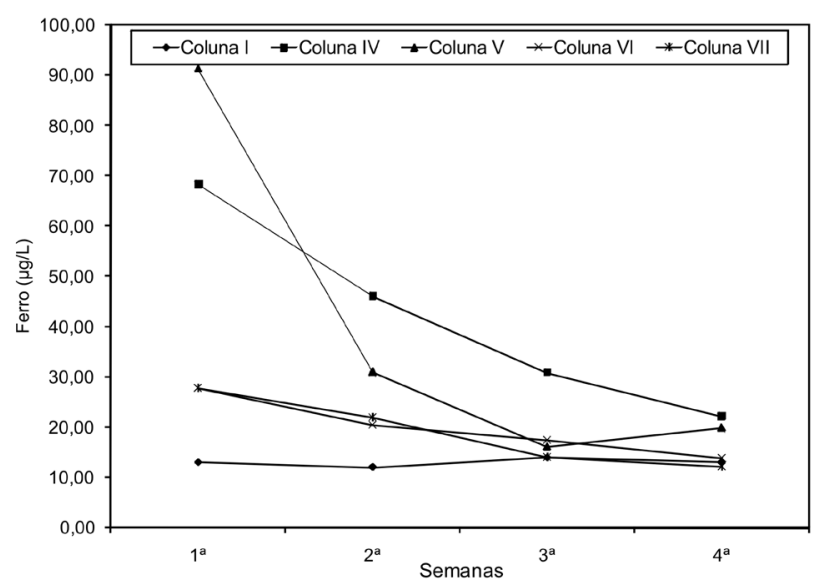

(b)

Figura 10 - (a) Concentração de manganês no lixiviado das colunas I, IV, V, VI e VII;

(b) Concentração de ferro no lixiviado das colunas I, IV, V, VI e VII.

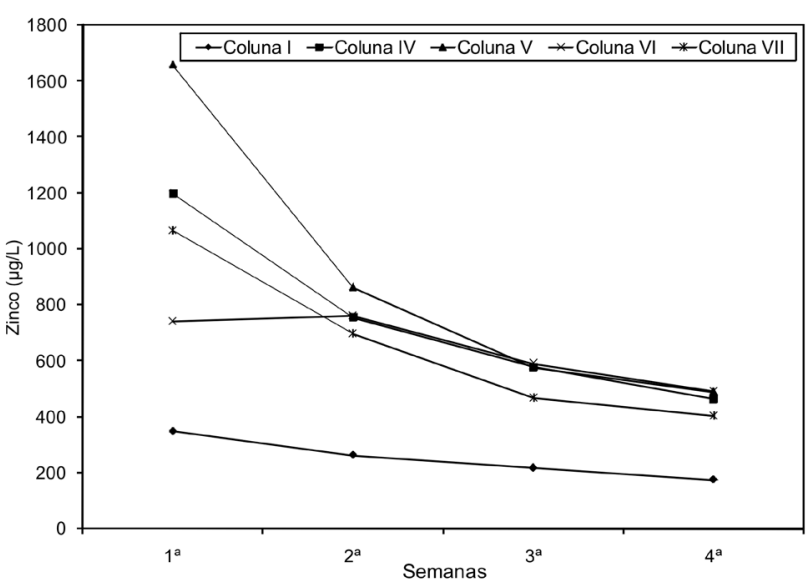

(a)

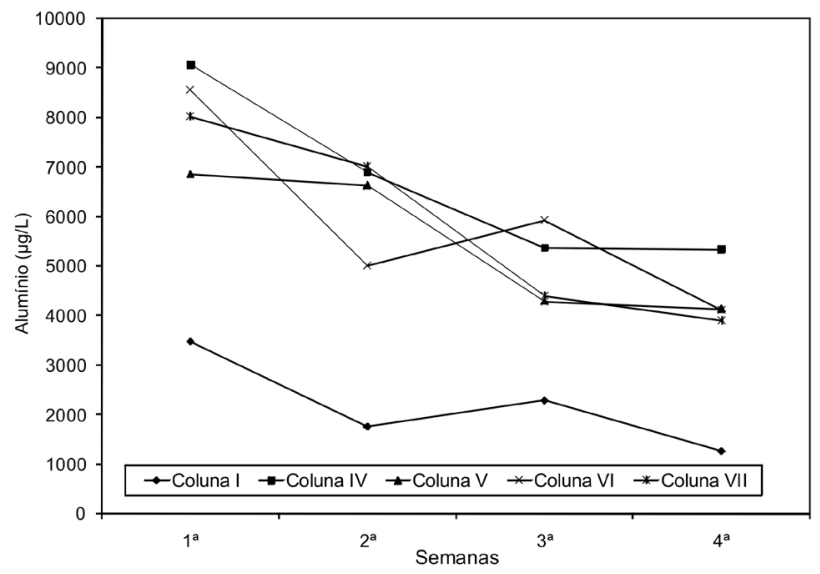

(b)

Figura 11 - (a) Concentração de zinco no lixiviado das colunas I, IV, V, VI e VII; (b) Concentração de alumínio no lixiviado das colunas I, IV, V, VI e VII. 


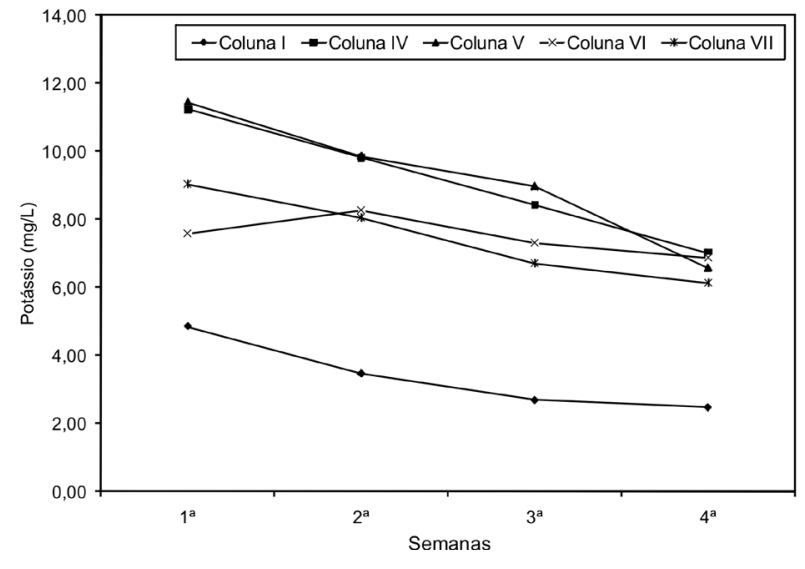

(a)

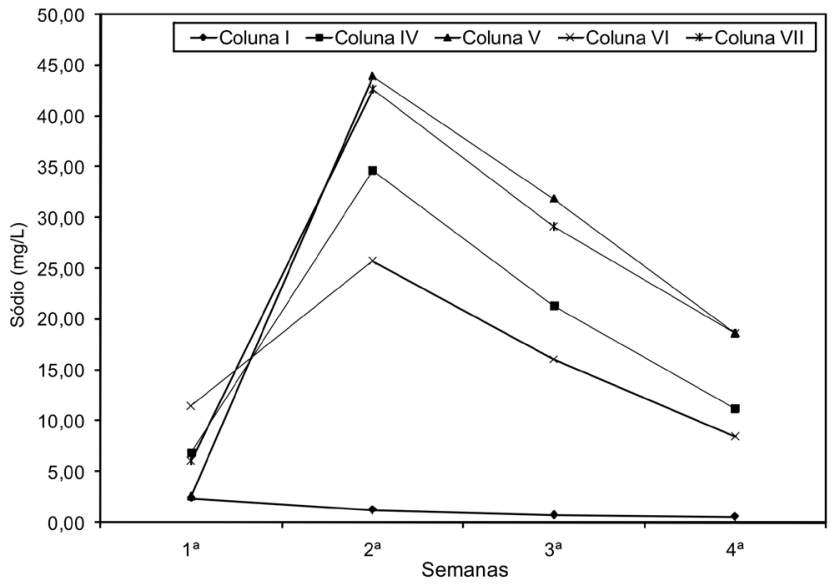

(b)

Figura 12 - (a) Concentração de potássio no lixiviado das colunas I, IV, V, VI e VII;

(b) Concentração de sódio no lixiviado das colunas I, IV, V, VI eVII.

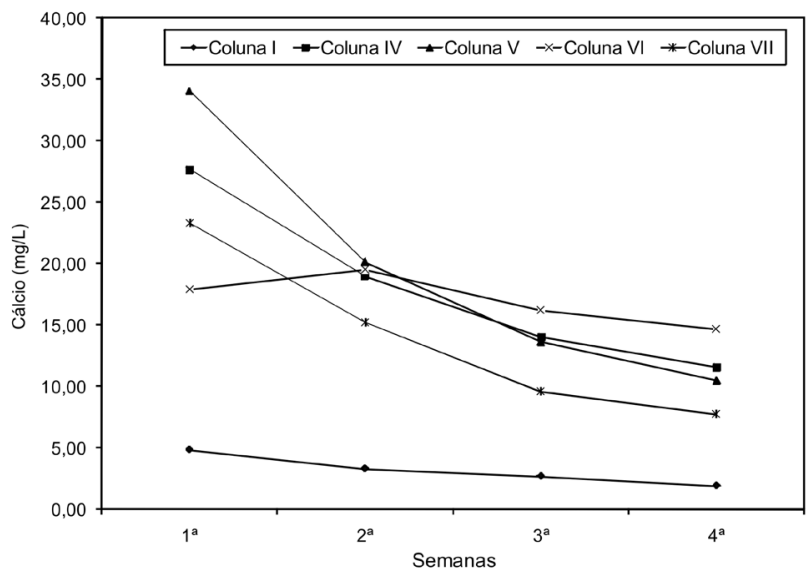

(a)

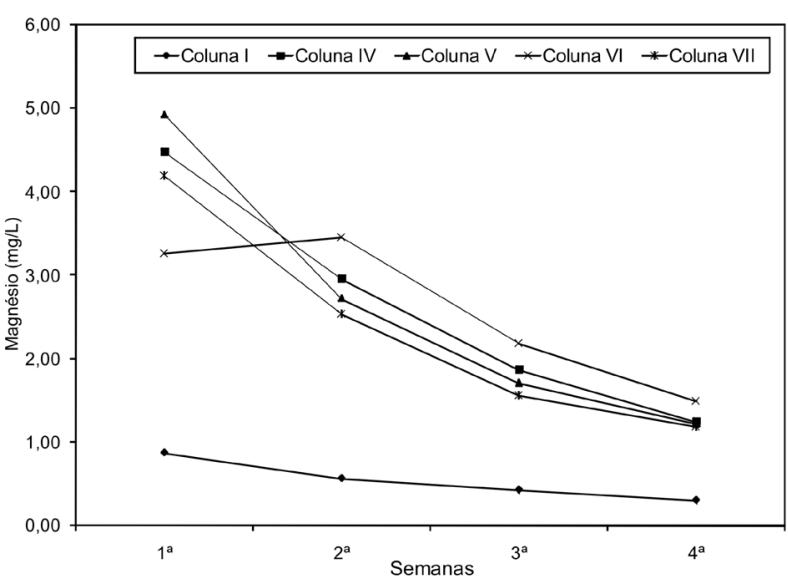

(b)

Figura 13 - (a) Concentração de cálcio no lixiviado das colunas I, IV, V, VI e VII; (b) Concentração de magnésio no lixiviado das colunas I, IV, V, VI e VII.

nerais sulfetados que contenham zinco estejam sendo oxidados dentro da coluna.

Observando-se a figura 12(b), percebe-se que as concentrações de sódio da primeira semana de ensaio para todas as colunas são levemente superiores às da Coluna I (referência). Na segunda semana ocorreu um grande aumento nas concentrações das colunas IV, V, VI e VII, que posteriormente apresentou tendência a decrescer até o final do ensaio. Especula-se que a causa destes picos de sódio sejam devidos à introdução de bentonita nestas colunas.

Comparando-se a figura 12(b) com a figura 2, que traz a variação do $\mathrm{pH}$ para as colunas IV, V, VI e VII em relação à Coluna I, não se observa uma correlação entre o pH e o aumento de sódio. Sendo assim, acredita-se que a dessorção do sódio da bentonita ocor- ra em função do tempo e por isso a sua concentração tenha se elevado tanto na segunda semana.

A concentração de sódio no lixiviado das colunas V e VII, a partir da segunda semana de ensaio, se apresentou maior que a concentração no lixiviado das colunas IV e VI, provavelmente porque nas colunas $\mathrm{V}$ e VII, onde se utilizou dolomita na camada de cobertura,

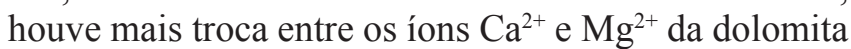
pelos íons $\mathrm{Na}^{+}$da bentonita.

As concentrações de cálcio nas colunas IV a VII (Fig. 13a) foram superiores às concentrações deste elemento na Coluna I, provavelmente devido à contribuição da bentonita e também aos materiais alcalinos utilizados no topo destas últimas colunas.

Com exceção dos sulfatos de estrôncio $\left(\mathrm{SrSO}_{4}\right)$, sulfatos de bário $\left(\mathrm{BaSO}_{4}\right)$ e sulfato de chumbo $\left(\mathrm{PbSO}_{4}\right)$, 
os sais de sulfato variam de moderadamente solúveis a solúveis (Feitosa \& Manoel Filho, 1997). Comparandose as concentrações de sulfato e as concentrações de cálcio encontradas para as colunas IV, V, VI e VII (Figs. 8 e 13a), pode-se concluir que, provavelmente, o cálcio não esteja se precipitando com o sulfato.

De maneira geral, concentrações maiores de material alcalino no sistema de cobertura das colunas foram mais efetivas para se reduzir a concentração de metais nos lixiviados. Por outro lado, o uso de cal hidratada ou dolomita foi indiferente.

Para a Coluna A (amostra saturada de água), todos os metais analisados apresentam concentração muito inferior à concentração da Coluna I (referência), demonstrando menores taxas de lixiviação sob condições anaeróbias.

CONCLUSÕES A aplicação de bentonita surtiu efeito para a diminuição da infiltração de água na coluna. Por outro lado, talvez a bentonita tenha contribuído para o aumento de metais no lixiviado, fato prejudicial aos sistemas de cobertura propostos. Deve-se salientar, entretanto, que ao longo do tempo de lixiviação houve tendências sistemáticas de diminuição de grande parte dos parâmetros analisados.

$\mathrm{O}$ aumento do teor de material alcalino no sistema de cobertura foi mais efetivo no aumento das condições de $\mathrm{pH}$ do lixiviado nas colunas, sendo o uso de cal hidratada ou dolomita indiferente para este fim.

Os sistemas de cobertura empregados nas colunas apontam para uma solução plausível no sentido de se reduzir à geração de drenagem ácida na pilha de estéril estudada. Trata-se de medida de remediação passiva, que provavelmente terá menor custo quando comparada com o método de tratamento ativo hoje empregado.

Entretanto, sabe-se que mais estudos devem ser realizados, atentando-se para aspectos específicos da mina e das soluções sugeridas. Tais trabalhos devem contemplar um projeto piloto realizado em campo, onde estes sistemas de cobertura possam ser melhor avaliados.

Destaca-se a importância deste estudo em termos da avaliação de uma metodologia de ensaio de laboratório, na tentativa de se comparar diferentes sistemas de cobertura para o abatimento de drenagem ácida de mina. Tais sistemas poderão ser empregados para outras minas.

\section{Referências}

AMERICAM PUBLIC HEALTH ASSOCIATION (APHA). 1992. Standard Methods for Examination of water and wastewater. 16th ed., Washington.

Camargo O.A., Moniz A.C., Jorge, J.A., Valadares, J.M.A.S. 1986. Métodos de Análise química, Mineralógica e Física de Solos do Instituto Agronômico de Campinas. Instituto Agronômico de Campinas, Boletim Técnico, 106, $94 p$.

Cipriani M. 2002. Mitigação dos impactos sociais e ambientais decorrentes do fechamento definitivo de minas de urânio. Tese de Doutoramento, Universidade Estadual de Campinas, 363p.

CONSELHO ESTADUAL DE POLÍTICA AMBIENTAL (COPAM). 1986. Resolução Normativa Nº 10, de 16 de dezembro de 1986. Disponível em www.siam.mg.gov. br/sla/download.pdf?idNorma=133. Acessado em 30/11/2008

ENVIRONMENTAL MINING COUNCIL OF BRITISH COLUMBIA (EMCBC). 2004. Protecting the Future through Action Today, Canada. Disponível em: <http:// www.miningwatch.org/emcbc/publications/amd water. htm. Acesso em 15/04/2006.

Evangelou V.P. 1995. Pyrite oxidation and its control: Solution Chemistry, Surface Chemistry, Acid Mine Drainage (AMD), Molecular Oxidation Mechanisms, Microbial Role, Kinetics, Control, Ameliorates and Limitations,
Microencapsulation. Lexington,University of Kentucky, Editora CRC, 293 p.

Feitosa F.A.C. \& Manoel Filho J. 1997. Hidrogeologia: conceitos e aplicações. Fortaleza/CE, CPRM, LABHIDEFPE, 412p.

Pejon O.J. 1992. Mapeamento Geotécnico da Folha de Piracicaba-SP (Escala 1:100000): Estudo de Aspectos Metodológicos, de Caracterização e de Apresentação dos Atributos. Tese de Doutoramento, Universidade de São Paulo, 224 p.

Sengupta M. 1993. Environmental Impacts of Mining: monitoring, restoration, and control. Lewis Publishers, Boca Raton, 494 p.

Souza V.P. 1996. Drenagens Ácidas do Estéril Piritoso da Mina de Urânio de Poços de Caldas: Interpretação e Implicações Ambientais. Dissertação de Mestrado, Universidade de São Paulo, 143p.

ENVIRONMENTAL PROTECTION AGENCY U.S. (U.S.EPA). 1994. Acid Mine Drainage Prediction, EPA530-R-94-036 (Technical Document). http://www. epa.gov/osw/nonhaz/industrial/special/mining/techdocs/ amd.pdf. Acessado em 15/04/2006.

Manuscrito AE058/2006

Submetido em 22 de novembro de 2006 Aceito em 20 de junho de 2008 